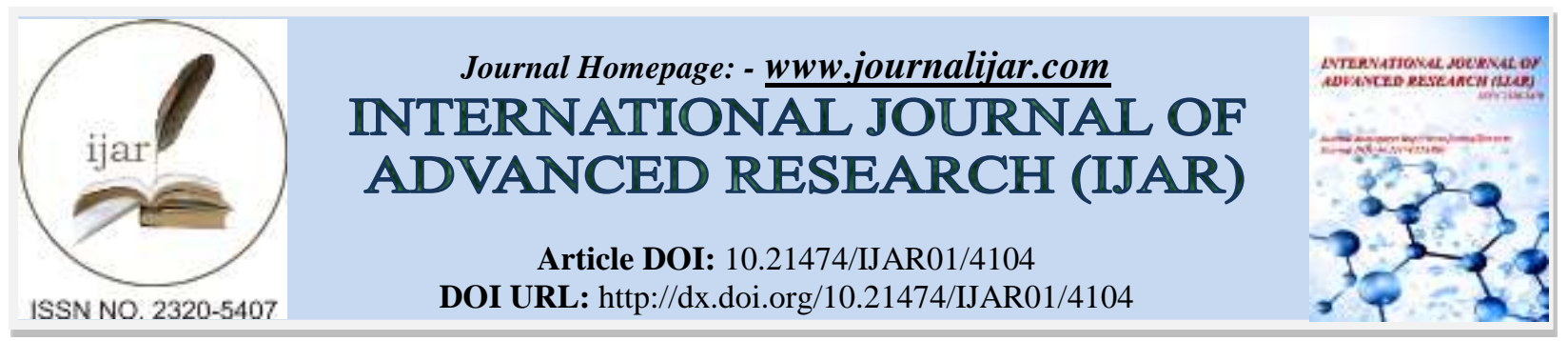

RESEARCH ARTICLE

\title{
A REVIEW ON NON CARIOUS LESIONS WITH EXHORTATION ON TOOTH WEAR INDICES, A DEPRECATED FACTOR.
}

\author{
A. H. Harini Priya and N. Priyadharsini.
}

Department of Oral and Maxillofacial Pathology, SRM Dental College, Ramapuram, Tamil Nadu, India.

\section{Manuscript Info}

Manuscript History

Received: 05 March 2017

Final Accepted: 08 April 2017

Published: May 2017

Key words:-

Non-Carious Lesions, Tooth Wear Index, Prader-Willi Syndrome,

Desensitization therapy

\section{Abstract}

Loss of tooth structure can occur as a result of various extraneous factors. Understanding the lesions along with pertinent treatment planning based on the nature of lesion and appropriate analysis of causative agent is important to avoid further detoriation of the condition. Tooth wear indices exhibits a pivotal role in diagnosis, grading and treatment planning for these lesions. But these indices are not much adopted from a clinical point of view. These indices evolved over a period of time incorporating diversified factors which can precisely or discursively impart its consequence in instigating the occurrence of non-carious lesions. Therefore, understanding these indices can bring a revolution in treatment modalities so adopted in conjointly improving the aesthetics as well as function. Thus, this article aims in discussing the evolution of indices over a period of time along with associated non-carious lesions and modified treatment modalities which have been adopted off late.

Copy Right, IJAR, 2016,. All rights reserved.

\section{Introduction:-}

Tooth structure can be dilapidated after eruption due to sundry reasons which encompasses inherent and environmental factors excluding trauma and dental caries. It thus includes, attrition, abrasion, erosion and abfraction that pillages enamel initially, howbeit others like internal and external resorption can involve the dentin and the cementum also. Tooth wear is a common term used to signify diversified destructions involving the calcified structures of the tooth, which may be physiological or pathological. Discrete classifications have been conferred for tooth wear, wherein it can be present as either individual or combine lesions. This article embellishes on the classifications, clinical features, treatment modalities for attrition, abrasion, erosion, Abfraction.

Foregoing to discussion on tooth wear lesions in Toto, it is imperative to know about various indices that have been conferred by diversified authors. Each of these indices have been established on each other's discernment about these lesions. Disregarding, not all these are broadly used and exiguous indices have secured importance over the period of time. One such is the Index given by Smith et al (as shown in table 1) which exhibits a general concept of measuring the tooth wear per se and the prejudice is that there is no encompassment or consideration of causative agents. (1) Another imperative part of tooth wear is erosion, which Eccles et al (as shown in Table 2) had stated a simple classification system for erosion that had occurred of non-industrial origin. And this classification is purely established on clinical location and countenance of the lesion.(2) Furthermore paramount index was given by Lussi et al (as shown in table 3) which was given for erosive lesions encompassing the tooth. This index has two sections, one grades the lesions involving the facial aspect of the teeth and other section assesses lesions involving the 
remaining aspects of the teeth. This method of indexing the tooth for erosive lesions is most frequently adopted in European countries. (3) (4) Consecutively, simplified scoring criteria for tooth wear index was evolved as a modification of Smith and Knight index, termed as Simplified Scoring Criteria For Tooth Wear (as in table 4) (2) (5) Latterly, a screening tool was developed by a group of esteemed clinicians from UK, Switzerland and Germany was proposed (as mentioned in Table 5,6,7), which was named as Basic Erosive Wear Examination, was concocted using preceding concepts which was put forward in the same cadre. This tool dissents from former one's where in here there is a sequence to be followed, initially the individual is subjected to clinical examination, followed by grading of individual affected tooth, and framing the treatment modalities for the same. The aspect of treatment planning seems to be more explanative.(6)

Grippo put forward a new classification of hard tissue lesions of teeth. He defined four categories of tooth wear:

\section{Attrition:-}

The loss of tooth substance as a result of tooth to tooth contact during normal or parafunctional masticator activity.

\section{Abrasion:-}

The pathological wear of tooth substance through bio-mechanical frictional processes, e.g. Tooth brushing.

\section{Erosion:-}

The loss of tooth substance by acid dissolution of either an intrinsic or extrinsic origin, e.g. Gastric acid or dietary acids.

\section{Abfraction:-}

The pathologic loss of tooth substance caused by bio-mechanical loading forces. (1)

\section{Attrition:-}

The term attrition is derived from the Latin verb "atterere" which means an action of rubbing against something. (7) Aforementioned earlier, attrition is characterized by loss of tooth structure as a result of mechanical wear between the opposing tooth during mastication and other parafunctional habits. (8) It usually presents in the occlusal surfaces in premolars and molars and incisor surface of anteriors. (9) Attrition as such occurs as a result of normal physiological process and not a pathological one. Various factors tend to trigger attrition, including presence of congenital anomalies like Amelogenesis imperfecta and Dentinogenesis imperfecta which renders the teeth more fragile to external or contributory factors leading to faster destruction of tooth structure. Others include psychological factors and bruxism where in the parent tend to expose the teeth to immense pressure leading to wearing of tooth structure at a much higher rate. (8) Bruxism is a parafunctional, non-productive habit of grinding or clutching the upper and lower teeth against each other \& is destructive in nature. It is usually the response of an individual to increased levels of stress and is associated stress-induced increase of nor-epinephrine turnover in brain. Stress as a lifestyle factor is increasingly seen as a predisposing influence towards bruxism. (10) Other parafunctional habits include pencil/pen biting, pipe smoking, habit of holding objects in between teeth as in the case of tailors, there tends to be accelerated wear of teeth. (11) Iatrogenic causes include improper or faulty restoration with highpoints which can lead to lack of occlusal stability where in the patient tends to grind his tooth to overcome the discomfort. (8) Attrition can also occur when natural teeth opposes porcelain, not only caused by diet but also a class III incisal relationship and lack of posterior support also lead to attrition.(8)

Clinically this lesion is more commonly seen in males compared to female, which might be associated with habits, strong masseter muscle activity, and greater muscle fibre mass and stronger ligaments. (12) First clinical manifestation of attrition may be the appearance of a small polished facet on a cusp tip or ridge or a slight flattening of an incisal edge. Mobility of teeth in their sockets, a manifestation of the resiliency of periodontal ligament. Occurs only in occlusal, incisal and proximal surfaces. Advanced attrition can lead to staining (extrinsic yellow or brown staining) from food or tobacco. (9)

\section{Abrasion:-}

Abrasion is defined as the pathological wearing away of tooth substance through some abnormal mechanical process. 
Usually associated with the use of abrasive dentifrice, improper Brushing technique, Habitual opening of bobby pins with teeth, Habitual pipe smoking, Improper use of dental floss and tooth picks (9)

The type of bristle material of toothbrush, stiffness of toothbrush bristles, the abrasiveness, and $\mathrm{pH}$ of dentifrice used are factors related to material. Dietary abrasion is not very prominent in modern days, as the typical western diet tends to be very soft, as opposed to primitive man's diet which was more abrasive, and thus contributed greatly to tooth wear. (7)

Though aetiology is varied, the pathogenesis remains the same, the loss of tooth substance by one means or the other is certainly pathologic but should present no problem at the time of diagnosis. The wearing away of tooth exposes the odontoblastic processes and there by leading to secondary dentin formation.(9) Abrasive defects are localised on the incisal edges of the anterior teeth. In this process where one object exerts a force on the surface of second one with simultaneous linear movement. Which in turn creates a compression zone will be formed behind it. When the cycle continues, subsurface cracks are formed which may subsequently occurs on the surface like a material loss. the additionally formed third particle can also act as a third wear component which further causes further destruction of tooth structure. (7) (11)

Based on the depth of abrasive lesion it can be distinguished into enamel abrasion, enamel and dentin abrasion, abrasion of whole dental crown with the risk of dental pulp exposing. (13)

Clinically the lesion caused by dentifrice manifests as a v-shaped or wedge - shaped ditch on the root side of the cementoenamel junction in teeth with some gingival recession. The angle formed by the depth of the lesion and the enamel surface is a sharp one and the dentin appears polished. Abrasion is common on the left for right-handed people. Lesions are wide than deep. Cervical areas are susceptible to tooth brush abrasion, particularly cuspids and premolars, where thin buccal plates, gingival recession and exposed root surfaced predispose cervical notching. Habits involving the incisal and occlusal surfaces are caused mainly because of dietary habits, and this type of lesion is not prominent in modern days because of modern diet which tends to have lesser abrasive nature compared to that of primitive man's diet. (9) (7) (14)

\section{Erosion:-}

Dental erosion is construed as an irreversible loss of dental hard tissue attributed to the occurrence of a chemical process without the involvement of bacteria. The dissolution of tooth structure usually occurs subsequently on contact with acids that are introduced into the oral cavity from intrinsic or extrinsic sources. (9)

Extrinsic sources are comprehensive of, Acid beverages (carbonated drinks), food such as citrus fruits, food items containing vinegar and medications such as vitamin $\mathrm{C}$, iron supplements and aspirin which gravitates to be acidic in sort. Further intrinsic sources encompasses, Regurgitated gastric acids as in case of case of anorexia, bulimia nervosa, and rumination, chronic vomiting, alcoholism. (15) According to a study done by Sandeep et al to estimate the prevalence of erosion in south Indian children showed a strong positive correlation between lemon consumption and tooth erosion, and there was also a significant association between commencement of dental erosion in children consuming soft drinks. There was no significant correlation betwixt type of school attended, socioeconomic status and brushing frequency, frequency of sweets consumption and method of consumption of endorsed drinks. (16) According to Hermont et al, there was a robust correlation between eating disorder and tooth erosion. Patient with eating disorder who self-induced vomiting had aggrandized prospect of tooth erosion than those patients who did not self- induce vomiting. (17) Fruit mulling is the third major cause of wear from erosion, is a quirk usually seen in health-conscious persons, who gravitate to consume fruit throughout the day with a suspension in swallowing the pulp of the fruit so it can be mulled between the teeth, analogous to chewing pattern in cow. Usually exhibits with cupping or cratering which is always present but with abraded enamel edges from mulling/ bruxing process.(18)

Though these factors influence to portrays a major role in prompting to bring about erosion of tooth, there are also involvement of other predisposing factors which would worsen the condition compared to unaffected individual, these are included in table 8. (14)

In preceding, it was stated that an eroded surface always gave a matted appearance, later it was shown that the lesion can also exhibit a blank appearance. The erosive lesion can be inconspicuous and can produce small concavities. Sometimes the surface is inappreciably rounded or flat and can give a "melted" appearance. (19) It generally 
perturbs the labial surfaces of maxillary anteriors and appears as shallow-spoon shaped depressions in the cervical portion of the crown, while the posterior teeth exhibit extensive loss of the occlusal surface. Occasionally entire buccal cusps are lost and replaced by ski slope-like depressions that aggrandize from the lingual cusp to the buccal cemento-enamel junction. When palatal surface of the tooth is affected, the exposed dentin has a concave surface and exhibits a peripheral white line of enamel. Active erosion type reveals a clean, unstained surface, whereas inactive becomes stained and discoloured. Dietary sources of acid - maxillary anteriors. Gastric regurgitation Palatal surface of maxillary Anteriors and occlusal surface of posterior teeth. (14) (15)

\section{Abfraction:-}

The word "Abfraction" was derived from the Latin "to break away". It was postulated that these lesions were caused by flexure of the tooth during loading leading to fatigue of the enamel and dentine at a location away from the point of loading. Lesions by the cause of Abfraction are also termed as 'cervical stress lesions' in the literature. (7) (14)

These lesions are usually located sub gingivally, where the influence of tooth brushing abrasion is bizarre, and hence influence to occur as a result of eccentrically applied occlusal stresses leading to tooth flexure, in preference due to abrasion alone. Weakening of hydroxyapatite present near the cervical region of the teeth is weakened due to ensile stresses, which consecutively produces the classical wedge-shaped defects having sharp edges approximal to the cementoenamel junction. (7) (20) Lateral force produces compressive stress on the side fronting which the tooth bends and the tensile stress is on the other side. These stresses create micro-fractures in the enamel or dentin at the cervical region. These fractures propagate in a direction perpendicular to the long axis of the tooth, contributing to a localized defect around the CEJ.(21) Romeed et al., investigated the biomechanics of abfraction lesions in the upper canine teeth under axial and lateral loading conditions, using a three-dimensional finite element analysis. It was found that the stresses were concentrated at the CEJ in all scenarios. Lateral loading produced the maximum stress, greater than axial loading, although the pulp tissues experienced minimum levels of stress. (22)

Thus, the theory of AF is not yet proven. The evidence against the theory of AF is as Follows:-

\# Few studies demonstrate that the occlusal loading is related to the AF lesions

\# Buccal surface is the most affected, while the lingual surface is the least affected. If flexure of the teeth is responsible, there would be equal damage to both buccal and lingual surfaces

* There is little or no evidence of these lesions in pre-historical skulls. NCCLs are found in historical skulls of the sixteenth century (after the invention of tooth powders and toothbrushes)

* Buccal surfaces of the premolars and the canines demonstrate worse lesions, as patients are likely to place the most brushing force on these surfaces. The lesions are progressively worse from the posterior to the anterior teeth

* The damage does not progress beyond the gingival crest (instead of at the crest of the bone), which is where the theory suggests the flexure should be the worst

* Not all persons with the lesions demonstrate occlusal wear (bruxing), and not all persons with severe occlusal wear exhibit NCCLs

\# Many cases show the absence of an antagonist to the affected tooth. If the damage continues, or the damage begins after the extraction of the antagonist, then bruxing cannot be the cause. (21)

\section{Management:-}

Anticipatory management of these lesions depends upon decisive diagnosis, revelation of causative agent, pertinent treatment planning, legitimate follow-up and proper counselling of the patient. Understanding the risk factor so associated with ontogenesis of the condition plays an imperative role in treating the same. Another eminent factor which must be considered is the interrelationship of the above-mentioned tooth wear conditions. Thus it is important to contemplate all the above-mentioned factor to ameliorate the quality and longevity of treatment.

Holbrook and Arnadottir stated that if non-carious destruction of teeth is to be avoided, following must be considered:

\# Recognizing and understanding that the condition exists.

\# Grading the severity of the condition.

\# Likely causes are diagnosed appropriately.

* Monitoring the preventative measures and the disease progress. (23) 
Rare syndromic conditions like Prader-Willi Syndrome (PWS) is the most common genetic human obesity syndrome characterised by lack of expression of paternally inherited genes on chromosome. It has a characteristic phenotype which encompasses neonatal and infantile hypotonia, early feeding problems (naso-gastric tube feeding for more than two months), childhood onset hyperphagia, obesity, growth hormone deficiency associated with short stature, high pain threshold and learning disabilities. The child usually exhibits with a narrow forehead, almondshaped eyes, down-turned corners of the mouth and a thin upper lip. (24)(25) These affected children are reported to have viscous saliva, decreased salivary flow rate, increased amounts of salivary ions and proteins.(26) Few studies have also stated that this syndrome is associated with progressive tooth loss or tooth wear. (27)

\section{Treatment:-}

In developing a treatment plan the following factors should be considered:

* Whether the wear is localised or generalised.

* Factors affecting the patient's speech, function and orofacial aesthetics.

* The behavioural, psychological, anatomical, developmental and physiological limitations of the patient. (8)

The early management of patients with tooth wear should always be preventive, soliciting to halt the disease process, and ward off any worsening. Habitual changes, that is, drinking of the acidic beverages by means of straw and prevention of swishing beverages in the mouth, will dwindle the rate of erosive tooth wear. Avoiding temperamental tooth brushing habits and the use of less abrasive toothpastes will also be beneficial.

Fluoride reduces the erosive characteristics of soft drinks, while topical applications succor protection against tooth wear after their intake. A $0.05 \%$, alcohol-free sodium fluoride mouth rinse can be used daily and helps to battle acidic damages while demineralizing toothpastes help to increase the hardness of the tooth surfaces which are exposed to acidic substances.

Patients whining of hypersensitivity from erosive lesions may ameliorated from the application of a highlyconcentrated fluoride varnish in the dental surgery, while daily use of a potassium-containing sensitive toothpaste may also bring relief.

Regular usage of acrylic splints can in turn avoid the progression of tooth loss and enables normal functioning of associated structures inclusive of TMJ and masticatory muscles. These splints can also be employed in application of fluoride or in case of desensitization therapy. Furthermore, for the patients with iterated reflux or vomiting splint may provide the protection against the action of stomach acid.

\section{Desensitisation Therapy:-}

The use of home or office application of so-called desensitizers that curtail the dentin hypersensitivity occurring in the advanced stages of hard dental tissues wear due to exposing dentinal tubules. They include the potassium, fluoride, stannous, oxalate ions, arginine, hydroxyapatite, CPP-ACP and calcium sodium phosphosilicate contained in pastes and gels for home and office use. (11)

\section{Erosion Therapy:-}

* Firstly diet counselling should be done.

* In case of patients with regurgitation as in case of GERD, the patient should be referred to a medical doctor for appropriate treatment.

* For patients with salivary hypo function, sugarless chewing gum can be prescribed to improve residual salivary flow, use of pilocarpine may be beneficial in case of patients with dry mouth caused by Sjogren's syndrome or post therapeutic head and neck radiation.

Esthetic management can be done with suitable restorative material, in case of patients with cervical abrasion. (7) (8) (9) 
Table 1:- Smith and Knight tooth wear index.

\begin{tabular}{|l|l|l|}
\hline Score & Surface & Criteria \\
\hline 0 & B/L/O/I & $\begin{array}{l}\text { No loss of enamel surface characteristics. } \\
\text { No loss of contour. }\end{array}$ \\
\hline 1 & B/L/O/I & Loos of enamel surface characteristics. \\
& C & Minimal loss of contour. \\
\hline 2 & B/L/O & Loss of enamel exposing dentine for less than one third of surface. \\
& I & Loss of enamel just exposing dentine. \\
& C & Lefect less than 1 mm deep. \\
\hline 3 & B/L/O & Loss of enamel and substantial loss of dentine. \\
& I & Defect less than 1-2 mm deep. \\
\hline 4 & B/L/O & Complete enamel loss - pulp exposure - secondary dentin exposure. \\
& I & Pulp exposure or exposure of secondary dentine. \\
& C & Defect more than 2mm deep - pulp exposure - secondary dentine exposure. \\
\hline
\end{tabular}

B: buccal; L: lingual; O: occlusal; I: incisal; C: cervical.

Table 2:- Eccles index for dental erosion of non-industrial origin

\begin{tabular}{|l|l|l|}
\hline Class & Surface & Criteria \\
\hline Class I & Facial & $\begin{array}{l}\text { Early stages of erosion, absence of developmental ridges, smooth, surfaces } \\
\text { of maxillary incisors and canines. }\end{array}$ \\
\hline Class II & $\begin{array}{l}\text { Dentine involved for less than one third surface; two types } \\
\text { Type 1(commonest): ovoid-crescentic in outline, concave in cross } \\
\text { differentiate from wedge shaped abrasion lesions } \\
\text { Type 2: irregular lesion entirely within crown. Punched out. }\end{array}$ \\
\hline Class IIIa & Facial & $\begin{array}{l}\text { More extensive destruction of dentine, affecting anterior teeth part of the } \\
\text { surface, but some are localised and hollowed out. }\end{array}$ \\
\hline Class IIIb & Lingual or palatal & $\begin{array}{l}\text { Dentine eroded for more than one third of the surface area. Gingival white, } \\
\text { etched appearance. Incisal edges translucent due to loss of is flat or } \\
\text { hollowed out, often extending into secondary dentine. }\end{array}$ \\
\hline Class IIId & Ancisal or occlusal & $\begin{array}{l}\text { Surfaces involved into dentine, appearing flattened or with cupping. Under- } \\
\text { mined enamel; restorations are raised above surrounding. }\end{array}$ \\
\hline
\end{tabular}

Table 3:- Erosion index as given by Lussi et al.

\begin{tabular}{|c|c|c|}
\hline Surface & Score & Criteria \\
\hline \multirow[t]{4}{*}{ Facial } & 0 & $\begin{array}{l}\text { No erosion. Surface with a smooth, silky glazed appearance, possible absence of } \\
\text { developmental ridges }\end{array}$ \\
\hline & 1 & $\begin{array}{l}\text { Loss of surface enamel. } \\
\text { Intact enamel cervical to the erosive lesion; } \\
\text { concavity on enamel where breadth clearly exceeds depth, thus distinguishing it } \\
\text { from toothbrush abrasion. } \\
\text { Undulating borders of the lesion are possible and dentine is not involved }\end{array}$ \\
\hline & 2 & Involvement of dentine for less than half of tooth surface \\
\hline & 3 & Involvement of dentine for more than half of tooth surface \\
\hline \multirow[t]{3}{*}{ Occlusal } & 0 & $\begin{array}{l}\text { No erosion. Surface with a smooth, silky glazed appearance, possible absence of } \\
\text { developmental ridges }\end{array}$ \\
\hline & 1 & $\begin{array}{l}\text { Slight erosion, rounded cusps, edges of restorations rising above the level of } \\
\text { adjacent tooth surface, grooves on occlusal aspects. Loss of surface enamel. } \\
\text { Dentine is not involved }\end{array}$ \\
\hline & 2 & Severe erosions, more pronounced signs than in grade 1 . Dentine is involved \\
\hline
\end{tabular}


Table 4:- Simplified scoring criteria for tooth wear index

\begin{tabular}{|c|c|}
\hline Score & Criteria \\
\hline 0 & No wear into dentine. \\
\hline 1 & Dentine just visible (including cupping) or \\
dentine exposed.
\end{tabular}

Table 5:- Clinical Sequence While Using Basic Erosive Wear Examination (Bewe)

\begin{tabular}{|l|l|}
\hline 1 & Diagnose the presence of tooth wear; eliminate teeth with trauma and developmental defects from the score \\
\hline 2 & Examine all teeth and all surfaces of teeth in the mouth for tooth wear \\
\hline 3 & Identify in each quadrant the most severely affected tooth with wear \\
\hline 4 & Conduct BEWE score \\
\hline
\end{tabular}

Table 6:- Criteria for Grading Erosive Wear.

\begin{tabular}{|l|l|}
\hline SCORE & FEATURES \\
\hline 0 & No erosive tooth wear \\
\hline 1 & Initial loss of surface texture \\
\hline 2 & Distinct defect, hard tissue loss $<50 \%$ of the surface area \\
\hline 3 & Hard tissue loss $\geq 50 \%$ of the surface area \\
\hline
\end{tabular}

Table 7:- Complexity Levels as a Guide to Clinical Management.

\begin{tabular}{|c|c|c|}
\hline $\begin{array}{l}\text { Complexity } \\
\text { level }\end{array}$ & $\begin{array}{l}\text { Cumulative score of } \\
\text { all sextants }\end{array}$ & Management \\
\hline 0 & $\begin{array}{l}\text { Less than } \\
\text { or equal to } 2\end{array}$ & $\begin{array}{l}\text { Routine maintenance and observation. } \\
\text { Repeat at 3-year intervals }\end{array}$ \\
\hline 1 & Between 3 and 8 & $\begin{array}{l}\text { Oral hygiene and dietary assessment, and advice, routine maintenance and } \\
\text { observation. } \\
\text { Repeat at } 2 \text {-year intervals }\end{array}$ \\
\hline 2 & Between 9 and 13 & $\begin{array}{l}\text { Oral hygiene and dietary assessment, and advice, identify the main } \\
\text { aetiological factor(s) for tissue loss and develop strategies to eliminate } \\
\text { respective impacts. } \\
\text { Consider fluoridation measures or other strategies to increase the } \\
\text { resistance of tooth surfaces. } \\
\text { Ideally, avoid the placement of restorations and monitor erosive wear with } \\
\text { study casts, photographs, or silicone impressions. } \\
\text { Repeat at 6-12 month intervals }\end{array}$ \\
\hline 3 & 14 and over & $\begin{array}{l}\text { Oral hygiene and dietary assessment, and advice, identify the main } \\
\text { aetiological factor(s) for tissue loss and develop strategies to eliminate } \\
\text { respective impacts. } \\
\text { Consider fluoridation measures or other strategies to increase the } \\
\text { resistance of tooth surfaces. } \\
\text { Ideally, avoid restorations and monitor tooth wear with study casts, } \\
\text { photographs, or silicone impressions. } \\
\text { Especially in cases of severe progression consider special care that may } \\
\text { involve restorations. } \\
\text { Repeat at 6-12 month intervals }\end{array}$ \\
\hline
\end{tabular}

\section{Conclusion:-}

Non-carious lesions are a group of lesions where each lesion constructs a characteristic finding, making each one distinctly discrete from others in terms of aetiology, clinical features, pathogenesis and there by requiring a divergent treatment planning for each lesion. As mentioned earlier the extent of early diagnosis is far more important to avoid inadvertent progression of the lesion and likewise, pertinent treatment planning is also very much important to enhance the aesthetics and efficiency of an individual's dentition and masticatory ability. 


\section{Reference:-}

1. López-frías FJ, Castellanos-cosano L, Martín-gonzález J, Llamas- JM. Clinical measurement of tooth wear : Tooth wear indices. 2012;4(1).

2. Bardsley PF. The evolution of tooth wear indices. Clin Oral Investig. 2008;12(SUPPL.1):15-9.

3. Lussi A, Schaffner M, Hotz P, Suter P. Dental erosion in a population of Swiss adults. Community Dent Oral Epidemiol [Internet]. 1991;19(5):286-90.

4. Lussi A. Dental erosion; clincial diagnosis and case history taking. EurJOral Sci. 2002;104:191-8.

5. Bardsley PF, Taylor S, Milosevic a. Epidemiological studies of tooth wear and dental erosion in 14-year-old children in North West England. Part 1: The relationship with water fluoridation and social deprivation. Br Dent J. 2004;197:413-416; discussion 399.

6. Bartlett D. A proposed system for screening tooth wear. Br Dent J [Internet]. 2010;208(5):207-9.

7. Hanif A, Rashid H, Nasim M. To o th surfacelos srevisited: Clas sific a tion, e tiology, a n d management. 2015;37-43.

8. Jain R, Hegde MN. Dental Attrition- Aetiology, Diagnosis and Treatment Planning: A Review. 2015;14(2):60-6.

9. Shafer;Hine;Levy. Shafer's Textbook of Oral Pathology. Shafers Textb Oral Pathol. 2012;1695-935.

10. Litonjua LA, Andreana S, Bush PJ, Cohen RE. Tooth wear: attrition, erosion, and abrasion. Quintessence international (Berlin, Germany: 1985). 2003 Jun;34(6):435-46.

11. Morozova SY, Ph D, Holik MP, Radim M, Ph D, Tomastik MJ, et al. Tooth Wear- Fundamental Mechanisms And Diagnosis. 2016;15(5):84-91.

12. Van 'T Spijker A, Kreulen CM, Creugers NHJ. Attrition, occlusion, (dys)function, and intervention: A systematic review. Clin Oral Implants Res. 2007;18(SUPPL. 3):117-26.

13. Barbour ME, Finke M, Parker DM, Hughes JA, Allen GC, Addy M. The relationship between enamel softening and erosion caused by soft drinks at a range of temperatures. J Dent. 2006;34(3):207-13.

14. Dds HK, Dds HT. Case Report Abrasion of Teeth ( Tooth Wear ). 2014;2(2):130-4.

15. Neville, Oral and Maxillofacial Pathology, 2nd Ed(1).pdf.

16. Kumar S, Acharya S, Mishra P, Debnath N, Vasthare R. Prevalence and risk factors for dental erosion among 11- to 14-year-old school children in South India. J Oral Sci [Internet]. 2013;55(4):329-36.

17. Hermont AP, Oliveira PAD, Martins CC, Paiva SM, Pordeus IA, Auad SM. Tooth erosion and eating disorders: A systematic review and meta-analysis. PLoS One. 2014;9(11).

18. Abrahamsen TC. The worn dentition - Pathognomonic patterns of abrasion and erosion. Int Dent J. 2005;55(4 SUPPL. 1):268-76.

19. Johansson AK, Omar R, Carlsson GE, Johansson A. Dental erosion and its growing importance in clinical practice: from past to present. Int J Dent [Internet]. 2012;2012:632907.

20. Journal I, Pathology M. 6 7-10. 2012;3(4):64-6.

21. Sarode GS, Sarode SC. Abfraction: a review. Journal of Oral and Maxillofacial Pathology. 2013 May 1;17(2):222.

22. Romeed SA, Malik R, Dunne SM. Stress analysis of occlusal forces in canine teeth and their role in the development of non-carious cervical lesions: Abfraction. Int J Dent. 2012;2012.

23. Holbrook WP, Arnadóttir IB, Kay EJ. Prevention. Part 3: prevention of tooth wear. Br Dent J. 2003;195(2):7581.

24. Pang S, Ls L, Stoner E, Nonsalt-losing NMI, Adams DM, Young PC, et al. Neonatal Presentation of PraderWilli Syndrome. 2015;

25. Saeves R, Espelid I, Storhaug K, Sandvik L, Nordgarden H. Severe tooth wear in Prader-Willi syndrome . A case - control study. 2012;

26. Kikwilu EN1 HJ. Int J Paediatr Dent. Int J Paediatr Dent. 1997. p. 19-24.

27. Young W, Khan F, Brandt R, Savage N, Razek AA, Huang Q. Syndromes with salivary dysfunction predispose to tooth wear: Case reports of congenital dysfunction of major salivary glands, Prader-Willi, congenital rubella, and Sjogren's syndromes. Oral Surg Oral Med Oral Pathol Oral Radiol Endod. 2001;92(1):38-48. 